\title{
Pilot randomized trial of short-term changes in inflammation and lipid levels during and after aspirin and pravastatin therapy
}

Kerry S. Flannagan ${ }^{1}$, Lindsey A. Sjaarda', Micah J. Hill ${ }^{2,3}$, Matthew T. Connell ${ }^{1,2}$, Jessica R. Zolton², Neil J. Perkins ${ }^{1}$, Sunni L. Mumford ${ }^{1}$, Torie C. Plowden', Victoria C. Andriessen ${ }^{1}$, Jeannie G. Radoc ${ }^{1}$ and Enrique F. Schisterman ${ }^{1 *}$

\begin{abstract}
Background: Inflammation and elevated blood lipids are associated with infertility. Aspirin and statin therapy may improve infertility treatment outcomes among overweight and obese women with systemic inflammation, but little is known about the short-term effects of statins in this population. We conducted a pilot study of aspirin, pravastatin, or combined treatment among a group of overweight and obese, reproductive-aged women. Our goal was to characterize short-term changes in inflammatory and lipid biomarkers during and after treatment.

Methods: In this open-label trial, women aged $18-40$ years with a body mass index $\geq 25 \mathrm{~kg} / \mathrm{m}^{2}$ were randomized to receive either $162 \mathrm{mg}$ aspirin, $40 \mathrm{mg}$ pravastatin, or both. The study medication was taken daily for 2 weeks, and participants were then followed for a two-week washout period. Participants provided blood samples at baseline, after the intervention period, and after the washout period. The outcomes were changes in biomarkers of inflammation and lipids measured in blood components at each timepoint.

Results: Nine, 8, and 8 women were randomized to the aspirin, pravastatin, and combined arms, respectively. Analyses were conducted among 8,7, and 7 women in the aspirin, pravastatin, and combined arms for whom biomarker data was available at baseline. High-sensitivity C-reactive protein (hsCRP) levels were lower after treatment in all arms and continued to decrease after washout in the pravastatin and combined arms. Results were consistent between the whole sample and women with baseline hsCRP between 2 and $10 \mathrm{mg} / \mathrm{L}$. Low-density lipoprotein (LDL) cholesterol was lower after treatment in the pravastatin and combined arms and rose slightly after washout.

Conclusions: Our results provide preliminary evidence that short-term aspirin and pravastatin therapy reduces hsCRP and LDL cholesterol among overweight and obese women of reproductive age, including those with low-grade inflammation. Because of these short-term effects, these drugs may improve infertility treatment outcomes in this population, which we will assess in a future randomized trial.
\end{abstract}

Keywords: Pravastatin, Aspirin, Infertility treatment, Inflammation, Cholesterol, Overweight and obesity, Pilot study

\footnotetext{
* Correspondence: schistee@mail.nih.gov

'Epidemiology Branch, Division of Intramural Population Health Research,

Eunice Kennedy Shriver National Institute of Child Health and Human

Development, National Institutes of Health, 6710B Rockledge Drive, MSC7004,

Bethesda, MD 20894, USA

Full list of author information is available at the end of the article
}

(c) The Author(s). 2019 Open Access This article is distributed under the terms of the Creative Commons Attribution 4.0 International License (http://creativecommons.org/licenses/by/4.0/), which permits unrestricted use, distribution, and reproduction in any medium, provided you give appropriate credit to the original author(s) and the source, provide a link to the Creative Commons license, and indicate if changes were made. The Creative Commons Public Domain Dedication waiver (http://creativecommons.org/publicdomain/zero/1.0/) applies to the data made available in this article, unless otherwise stated. 


\section{Plain English summary}

Low-grade inflammation is a condition in which the body produces low amounts of inflammatory factors for an extended period. Women with overweight/obesity often have both low-grade inflammation and elevated blood lipids, such as cholesterol and triglycerides. Inflammation and lipids may impair fertility because they are related to reproductive disorders. When these women undergo infertility treatment, taking aspirin and cholesterol-lowering statin drugs could improve their outcomes by reducing inflammation and cholesterol. However, because statins are not recommended during pregnancy, it is important to know whether their effects occur quickly after beginning treatment and persist after a woman stops taking the drug. This would indicate that short-term statin therapy stopped before pregnancy, along with aspirin, a common anti-inflammatory medication, could still support the events of early pregnancy. We conducted a preliminary study of short-term changes in inflammation and blood lipids during and after aspirin and pravastatin therapy in a group of overweight women.

We randomly assigned women to take either $162 \mathrm{mg}$ aspirin, $40 \mathrm{mg}$ pravastatin, or both daily for 2 weeks. We measured inflammation and lipids in blood samples before and after the 2 weeks when participants took the medication, and 2 weeks after they stopped.

All women had lower inflammation after treatment, and women taking pravastatin had lowered inflammation 2 weeks post-treatment. These women also had lower cholesterol levels after treatment. Our results indicate that aspirin and pravastatin might improve infertility treatment outcomes among overweight women with low-grade inflammation, which we intend to test in a larger trial.

\section{Background}

Inflammation is associated with multiple types of reproductive disorders and infertility [1-3]. Higher lipid levels are also associated with lower oocyte quality $[4,5]$ and lower likelihood of pregnancy [6, 7].

Interventions aimed at reducing systemic inflammation and blood lipid levels might be effective at improving outcomes of first-line infertility treatments such as ovulation induction (OI) and/or intrauterine insemination (IUI), which currently have relatively low success rates [8-11]. In the Effects of Aspirin in Gestation and Reproduction (EAGeR) Study, inflammation measured by high-sensitivity C-reactive protein (hsCRP) was associated with lower fecundity [12]. However, low-dose aspirin therapy restored normal pregnancy and live birth rates only among lean women with low-grade inflammation [12]. For women with higher adiposity, a higher dose of aspirin may be necessary, and a dual therapy targeting both inflammation and lipid levels may provide additional benefit and be needed to improve reproductive outcomes.

In addition to aspirin, statin drugs may be beneficial in addressing infertility. Statins have lipid-lowering effects, and are also anti-inflammatory agents [13-15]. However, while the long-term effects of these drugs are well studied $[13,16]$, there is very little information on their effects in the short term. Because statins are contraindicated in pregnancy due to potential teratogenic effects [17], understanding the timing of anti-inflammatory and lipid-lowering actions during short-term statin therapy is crucial for determining how these drugs might be used in infertility treatment. To address this gap, we conducted a pilot randomized trial of aspirin and pravastatin therapy among overweight and obese, reproductive-aged women. Our aim was to obtain preliminary information on short-term changes in inflammatory and metabolic biomarkers during and after cessation of treatment.

\section{Methods}

The study design was an unblinded, randomized trial. Participants were women seeking infertility evaluation at the Walter Reed National Military Medical Center (WRNMMC) in Bethesda, MD. Study personnel approached women at their initial clinic visit regarding the study and assessed eligibility criteria. Eligible women were between 18 and 40 years old; had a body mass index (BMI) $\geq 25 \mathrm{~kg} / \mathrm{m}^{2}$; had a negative urine hCG pregnancy test at screening; were not currently using aspirin, statins, other cholesterol medications, non-steroidal anti-inflammatory drugs, or oral contraceptives; free of major chronic health conditions; and did not have any other conditions for which aspirin or statins would be contraindicated. Women who met these criteria were invited to enroll. To ensure enrollment of enough women with hsCRP between 2 and $10 \mathrm{mg} / \mathrm{L}$, indicating low-grade inflammation, the target sample size was 39; however, enrollment was stopped at 27 due to practical considerations related to the larger trial. All participants provided informed written consent for screening and study procedures. The study was approved by the institutional review board at WRNMMC, where all study procedures and biomarker measurements took place.

Enrolled women were randomized with a computer algorithm to receive either $162 \mathrm{mg}$ aspirin, $40 \mathrm{mg}$ pravastatin, or both. The aspirin dosage is based on previous data showing lowered inflammatory markers at this dose [18], and the dosage of pravastatin was chosen because it is used in normal therapy. A block-randomized list of treatment assignments was generated and written in sealed envelopes prior to study initiation, and the next envelope in order was chosen as each participant was enrolled. The study 
medication was taken daily by mouth for 2 weeks at no specific time of day. Following this period, women were followed for an additional 2-week washout period. The treatment period was designed to mimic a realistic course of treatment in our future trial, where study medications would be taken from the beginning of the menstrual cycle until ovulation 2 weeks later. The washout period was designed to determine whether effects of the medications would last throughout events of pregnancy establishment during the 2 weeks following ovulation and treatment cessation. In addition to the study intervention, participants were asked to abstain from intercourse while taking the study medication. Participants provided blood samples before and after the intervention period, and after the washout period (baseline, week 2, and week 4, respectively). Reproductive history characteristics were obtained at baseline.

The outcomes of interest were inflammatory and lipid biomarkers measured in blood components at baseline, week 2 , and week 4 . The inflammatory biomarkers included serum hsCRP, serum interleukin$1 \beta$ (IL-1), and serum interleukin-6 (IL-6). HsCRP was measured by immunoturbidimetric assay (Roche Diagnostics, Indianapolis, IN), IL-1 was measured by enzyme-linked immunosorbent assay (Quest Diagnostics, Baltimore, MD, USA), and IL-6 was measured by chemiluminescent immunoassay (Siemens Healthcare Global, Malvern, PA). Lipids include serum total cholesterol, serum low-density lipoprotein (LDL) cholesterol, serum high-density (HDL) lipoprotein cholesterol, and serum triglycerides. All lipids were measured by homogenous enzymatic colorimetric assay (Roche Diagnostics, Indianapolis, IN). We compared medians and ranges of the biomarkers at the three timepoints with respect to treatment arm. We also examined individual trajectories of hsCRP among women with baseline hsCRP between 2 and $10 \mathrm{mg} / \mathrm{L}$, indicating chronic, low-grade inflammation.

\section{Results}

Twenty-seven women were recruited and 2 withdrew before randomization. The final randomized sample included 9,8 , and 8 women in the aspirin, pravastatin, and combined arms, respectively. After withdrawals, the final numbers of women with available biomarker measurements at baseline, week 2 , and week 4 were 22,19 , and 11 , respectively. The mean $( \pm$ SD) age of randomized participants was $31.8 \pm 5.1$ years and mean $( \pm$ SD) BMI was $31.4 \pm 5.9 \mathrm{~kg} / \mathrm{m}^{2}$. The treatment arms were balanced with respect to most baseline demographic and reproductive characteristics, although the median age of women in the aspirin arm was somewhat lower compared to the other two groups (Table 1).

Compared with baseline, median hsCRP was lower after 2 weeks of treatment in all three study arms (Table 2); these differences were most pronounced in the aspirin and combined treatment groups. At week 4, median hsCRP in the aspirin group rose and was again similar to baseline, whereas among the pravastatin and combined groups it continued to decrease. Among women with baseline hsCRP between 2 and $10 \mathrm{mg} / \mathrm{L}(N=10)$, hsCRP levels decreased from baseline to week 2 in 2 of 3 women in the aspirin group, 4 of 4 women in the pravastatin group, and 2 of 2 women in the combined group (Fig. 1). Five of these women had biomarker measurements available at week 4 ( 2 in the aspirin group, 2 in the pravastatin group, and 1 in the combined group). One woman in the pravastatin group had higher hsCRP at week 4 compared to week 2; the other women had no change.

There were no differences in IL-1 concentrations over time in any group (Table 2). In the aspirin group, IL-6 concentrations were similar at baseline and week 2 but rose by week 4 . IL- 6 in the pravastatin group also did not change appreciably between baseline and week 2 but decreased between weeks 2 and 4 . In the combined group, median IL- 6 decreased from baseline to week 2 and remained similar at week 4 .

Median total cholesterol concentrations were similar throughout the study in the aspirin and pravastatin groups. In the combined group, total cholesterol was lower at weeks 2 and 4 compared to baseline. LDL cholesterol was consistent at all time points in the aspirin group. In the pravastatin and combined groups, median LDL cholesterol decreased between baseline and week 2, then rose slightly between weeks 2 and 4. HDL cholesterol lowest at week 4 in the aspirin group but did not change in the pravastatin and combined groups. Serum triglyceride trajectories were inconsistent between all treatment arms. In the aspirin group, the median concentration initially fell and then rose across the 3 timepoints, whereas the pravastatin group experienced the opposite pattern. In the combined group, median triglyceride concentrations rose consistently across follow-up.

\section{Discussion}

In this pilot randomized trial of short-term treatment with aspirin, pravastatin, or both, we found that hsCRP was reduced after 2 weeks of medication in all treatment arms. Two weeks after treatment cessation, hsCRP remained below baseline levels among participants in the groups receiving pravastatin. Results among women with elevated baseline hsCRP were consistent with results among the whole sample. 
Table 1 Baseline characteristics of participants by assigned treatment group

\begin{tabular}{|c|c|c|c|}
\hline \multirow[b]{3}{*}{ Characteristic } & \multicolumn{3}{|l|}{ Treatment group } \\
\hline & Aspirin only $(N=9)$ & Pravastatin only $(N=8)$ & Aspirin and pravastatin $(N=8)$ \\
\hline & Median (range) or $\mathrm{N}$ & Median (range) or N & Median (range) or N \\
\hline Age (y) & $29(23,41)$ & $33(29,39)$ & $34(24,40)$ \\
\hline Body mass index $\left(\mathrm{kg} / \mathrm{m}^{2}\right)$ & $28.3(26.1,35.5)$ & $29.3(25.8,46.7)$ & $31.0(26.6,48.1)$ \\
\hline Polycystic ovary syndrome & 3 & 1 & 2 \\
\hline Prior pregnancies & $1(0,3)$ & $1.5(0,3)$ & $0.5(0,3)$ \\
\hline Prior fullterm births & $0(0,2)$ & $0(0,1)$ & $0(0,2)$ \\
\hline Prior pregnancy losses or terminations & $1(0,1)$ & $0.5(0,3)$ & $0(0,2)$ \\
\hline
\end{tabular}

Table 2 Medians of inflammatory and cardiometabolic biomarkers over time by assigned treatment

\begin{tabular}{|c|c|c|c|c|c|c|}
\hline \multirow[b]{3}{*}{ Biomarker } & \multicolumn{6}{|c|}{ Treatment group } \\
\hline & \multicolumn{2}{|c|}{ Aspirin only } & \multicolumn{2}{|c|}{ Pravastatin only } & \multicolumn{2}{|c|}{ Aspirin and pravastatin } \\
\hline & $\bar{N}$ & $\overline{\text { Median (range) }}$ & $\bar{N}$ & $\overline{\text { Median (range) }}$ & $\overline{\mathrm{N}}$ & Median (range) \\
\hline \multicolumn{7}{|c|}{ hsCRP (mg/L) } \\
\hline Baseline & 8 & $2.1(0.2,4.9)$ & 7 & $3.3(0.4,8.8)$ & 6 & $3.6(0.3,12.0)$ \\
\hline Week 2 & 7 & $1.0(0.2,4.2)$ & 7 & $2.9(0.3,5.1)$ & 5 & $1.4(0.3,16.2)$ \\
\hline Week 4 & 3 & $2.3(0.8,4.0)$ & 4 & $1.1(0.6,4.5)$ & 4 & $0.9(0.3,11.1)$ \\
\hline \multicolumn{7}{|l|}{$\mathbb{I L}-1(p g / m L)$} \\
\hline Baseline & 8 & $3.9(3.9,3.9)$ & 7 & $3.9(3.9,4.0)$ & 7 & $3.9(3.9,4.0)$ \\
\hline Week 2 & 7 & $3.9(3.9,3.9)$ & 7 & $3.9(3.9,4.0)$ & 5 & $3.9(3.9,4.0)$ \\
\hline Week 4 & 3 & $3.9(3.9,4.0)$ & 4 & $4.0(3.9,4.0)$ & 4 & $3.9(3.9,4.0)$ \\
\hline \multicolumn{7}{|l|}{$\mathbb{I L}-6(p g / m L)$} \\
\hline Baseline & 8 & $1.9(0.7,3.0)$ & 7 & $3.4(0.7,41.1)$ & 6 & $3.2(0.7,15.4)$ \\
\hline Week 2 & 7 & $2.0(0.7,3.1)$ & 7 & $3.4(0.7,8.7)$ & 5 & $2.4(0.7,7.6)$ \\
\hline Week 4 & 3 & $2.8(0.7,3.1)$ & 4 & $2.1(0.7,5.5)$ & 4 & $2.4(0.7,10.2)$ \\
\hline \multicolumn{7}{|c|}{ Total cholesterol (mg/dL) } \\
\hline Baseline & 8 & $192(120,238)$ & 6 & $180(159,256)$ & 7 & $166(145,188)$ \\
\hline Week 2 & 6 & $183(153,209)$ & 5 & $173(124,224)$ & 5 & $148(137,191)$ \\
\hline Week 4 & 3 & $186(157,232)$ & 4 & $179(140,190)$ & 3 & $147(116,154)$ \\
\hline \multicolumn{7}{|c|}{ LDL cholesterol (mg/dL) } \\
\hline Baseline & 8 & $125(79,189)$ & 6 & $115(92,145)$ & 7 & $102(7,122)$ \\
\hline Week 2 & 6 & $114(83,143)$ & 5 & $87(58,130)$ & 5 & $78(60,101)$ \\
\hline Week 4 & 3 & $113(104,189)$ & 4 & $104(73,130)$ & 3 & $90(52,101)$ \\
\hline \multicolumn{7}{|c|}{ HDL cholesterol (mg/dL) } \\
\hline Baseline & 8 & $54(30,83)$ & 6 & $61(46,87)$ & 7 & $61(33,82)$ \\
\hline Week 2 & 6 & $64(34,79)$ & 5 & $64(51,82)$ & 5 & $60(36,75)$ \\
\hline Week 4 & 3 & $40(38,62)$ & 4 & $60(47,72)$ & 3 & $59(32,60)$ \\
\hline \multicolumn{7}{|c|}{ Triglycerides (mg/dL) } \\
\hline Baseline & 8 & $111(33,311)$ & 6 & $87(31,146)$ & 7 & $75(73,121)$ \\
\hline Week 2 & 6 & $71(37,229)$ & 5 & $105(48,138)$ & 5 & $98(54,166)$ \\
\hline Week 4 & 3 & $92(31,97)$ & 4 & $73(35,142)$ & 3 & $113(73,206)$ \\
\hline
\end{tabular}




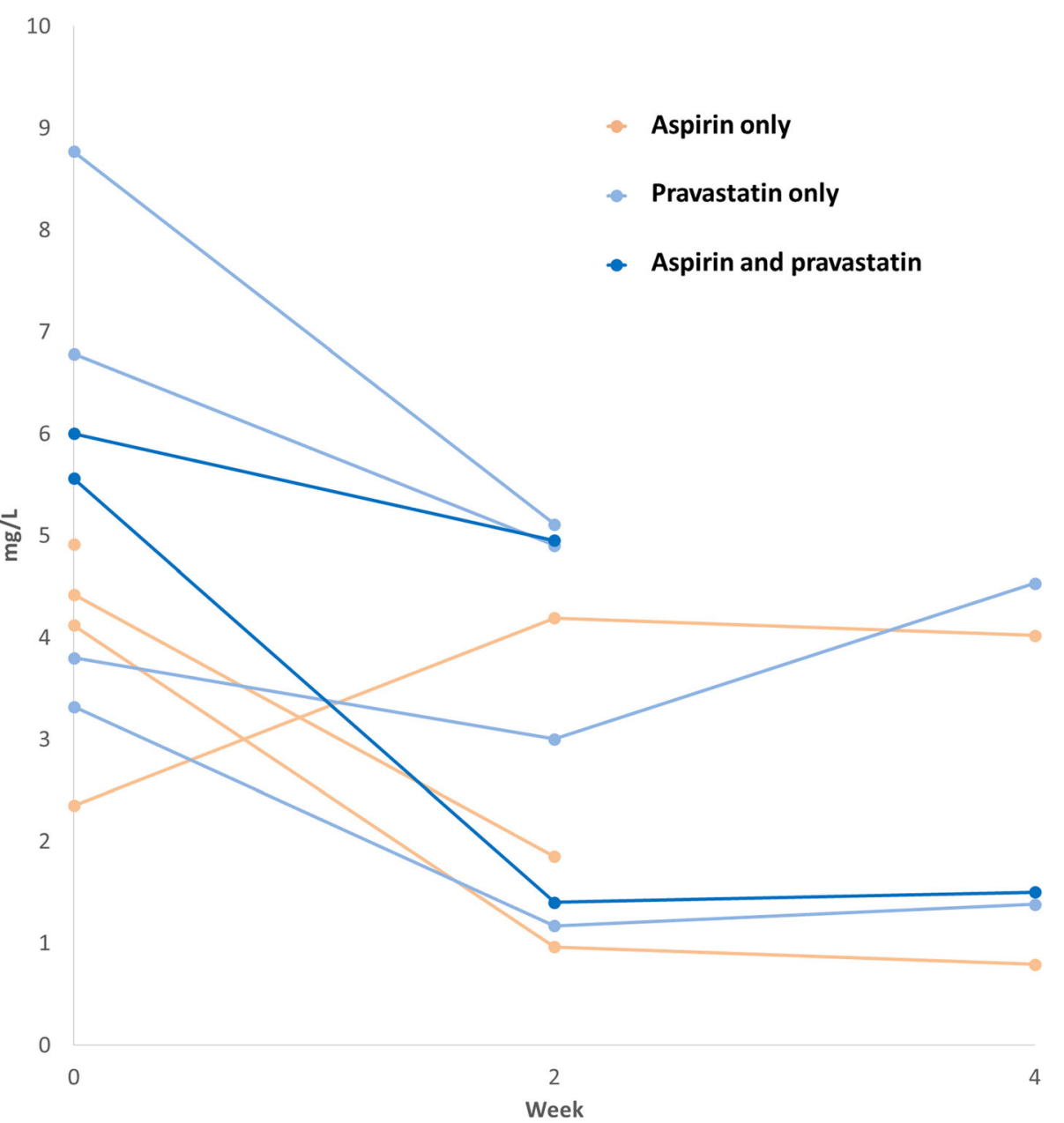

Fig. 1 Trajectories of hsCRP among women with baseline hsCRP between 2 and $10 \mathrm{mg} / \mathrm{L}$. Each series represents one participant; data are individual measurements of hsCRP in $\mathrm{mg} / \mathrm{L}$. Women were randomized to receive either daily aspirin, pravastatin, or both from baseline to week 2 , followed by a washout period from week 2 to week 4

Our results are consistent with previous research indicating that statins have anti-inflammatory effects [13, 19], including studies conducted among women of reproductive age with polycystic ovary syndrome [20, 21]. Most work in this area has focused on longer-term statin use; however, one previous study assessed short-term treatment and inflammation [15]. In this trial, 40 men and women with elevated LDL cholesterol received either simvastatin for 2 weeks followed by placebo for 2 weeks or vice versa. During statin treatment, mean hsCRP decreased from $2.55 \mathrm{mg} / \mathrm{L}$ at baseline to $1.60 \mathrm{mg} / \mathrm{L}$ after 2 weeks, while there was no decrease during the placebo periods. These results are consistent with our findings that statin-mediated changes in inflammation occur in a relatively short timeframe. We also found evidence for continued suppression of inflammation 2 weeks after statin cessation, in contrast with a previous study of hyperlipidemic participants in which CRP rose within a week of stopping pravastatin [14].
Our results provide preliminary evidence for shortterm anti-inflammatory effects of statins in a population of reproductive-aged overweight women with low-grade inflammation, a group who might benefit from the use of statins in conjunction with infertility treatments such as OI/IUI. None of the participants in this study reported adverse effects of the study medications such as bleeding or muscle pain, suggesting that these treatments can be well-tolerated. Since statins are contraindicated in pregnancy because of possible teratogenicity [17], the timing of inflammation dynamics during and after statin therapy have potential implications for its use in this context. The utility of statin drugs may be related to whether short-term therapy, stopped at or before the first indication of pregnancy, can reduce inflammation during preconception and early pregnancy.

We also found that LDL cholesterol was lower after treatment among both groups receiving pravastatin, but rose after treatment cessation. The finding that statins lower 
LDL cholesterol within 2 weeks is consistent with previous work [15]. However, in a study of six-week pravastatin therapy among hyperlipidemic participants, there was no change in LDL 2 week after stopping treatment [14]. Potential explanations for this discrepancy include the duration of the statin treatment, demographic and health-related differences between the study populations, or chance.

One of the strengths of this study is its randomized design. The study also provides novel information on the timing of statins' anti-inflammatory effects among overweight, reproductive-aged women with low-grade inflammation. Understanding these effects in this population is important, since the use of statins to address inflammation and elevated lipids could improve infertility treatment outcomes in these women. One of the study's primary weaknesses was the high rate of loss to followup, which could have biased our results if dropout was related to inflammation or lipid levels. Because we were not able to screen for hsCRP as an inclusion criterion, the number of women with elevated hsCRP at baseline was small. Finally, we did not collect fasting blood samples, which could have induced extraneous variation in measurements of some blood lipids.

\section{Conclusions}

Overall, our findings provide preliminary evidence that short-term treatment with pravastatin and aspirin may reduce inflammation and LDL cholesterol in women seeking infertility treatment. We are currently in the process of designing a larger trial of medication use to improve fertility treatment outcomes in a similar population of women with chronic, low-grade inflammation, including those with and without obesity. In the long-term, if statins and aspirin prove beneficial for women with chronic inflammation who wish to become pregnant, these drugs could be added to clinical practice as part of first-line fertility treatments such as OI/IUI, in order to improve the success rates of these procedures.

\section{Abbreviations \\ BMI: Body mass index; EAGeR: Effects of Aspirin in Gestation and Reproduction Study; HDL: High-density lipoprotein; hsCRP: High-sensitivity C- reactive protein; IL-1: Interleukin-1; IL-6: Interleukin-6; IUI: Intrauterine insemination; LDL: Low-density lipoprotein; Ol: Ovulation induction; SD: Standard deviation; WRNMMC: Walter Reed National Military Medical Center}

\section{Acknowledgements}

The authors acknowledge the study staff and participants for their assistance and participation.

\section{Authors' contributions}

$\mathrm{KF}$ analyzed the data and drafted the manuscript, SM and ES also contributed to the manuscript. LS, MH, NP, SM, and ES designed the study. $\mathrm{MH}, \mathrm{TP}$, and $\mathrm{MC}$ conducted the study. All authors revised the manuscript for critical content. All authors read and approved the final manuscript.

\section{Funding}

This work was supported by the Intramural Research Program of the Eunice Kennedy Shriver National Institute of Child Health and Human Development, National Institutes of Health, Bethesda, Maryland. Walter Reed National Military Medical Center provided the venipuncture, serum testing, and medications. The funding body had no role in the design of the study; collection, analysis, and interpretation of data; or writing the manuscript. Jeannie G. Radoc has been funded by the NIH Medical Research Scholars Program, a public-private partnership supported jointly by the $\mathrm{NIH}$ and generous contributions to the Foundation for the NIH from the Doris Duke Charitable Foundation (DDCF Grant \# 2014194), Genentech, Elsevier, and other private donors.

\section{Availability of data and materials}

The datasets used and/or analyzed during the current study are available from the corresponding author on reasonable request.

\section{Ethics approval and consent to participate}

All participants provided informed written consent for screening and study procedures. The study was approved by the institutional review board at WRNMMC, where all study procedures and biomarker measurement took place.

\section{Consent for publication}

Not applicable.

\section{Competing interests}

The authors declare that they have no competing interests.

\section{Author details}

${ }^{1}$ Epidemiology Branch, Division of Intramural Population Health Research, Eunice Kennedy Shriver National Institute of Child Health and Human Development, National Institutes of Health, 6710B Rockledge Drive, MSC7004, Bethesda, MD 20894, USA. ${ }^{2}$ Program in Reproductive and Adult Endocrinology, Eunice Kennedy Shriver National Institute of Child Health and Human Development, National Institutes of Health, Bethesda, MD, USA.

${ }^{3}$ Walter Reed National Military Medical Center, Bethesda, MD, USA.

Received: 25 February 2019 Accepted: 23 August 2019

Published online: 02 September 2019

\section{References}

1. Galgani M, Insabato L, Cali G, Della Gatta AN, Mirra P, Papaccio F, et al. Regulatory $T$ cells, inflammation, and endoplasmic reticulum stress in women with defective endometrial receptivity. Fertil Steril. 2015;103(6): 1579-86.e1.

2. Halis $\mathrm{G}$, Arici A. Endometriosis and inflammation in infertility. Ann N Y Acad Sci. 2004;1034:300-15.

3. Shorakae S, Teede H, de Courten B, Lambert G, Boyle J, Moran L. The emerging role of chronic low-grade inflammation in the pathophysiology of polycystic ovary syndrome. Semin Reprod Med. 2015;33(4):257-69.

4. Browne RW, Bloom MS, Shelly WB, Ocque AJ, Huddleston HG, Fujimoto VY. Follicular fluid high density lipoprotein-associated micronutrient levels are associated with embryo fragmentation during IVF. J Assist Reprod Genet. 2009:26(11-12):557-60.

5. Cardozo E, Pavone ME, Hirshfeld-Cytron JE. Metabolic syndrome and oocyte quality. Trends Endocrinol Metab. 2011;22(3):103-9.

6. Pugh SJ, Schisterman EF, Browne RW, Lynch AM, Mumford SL, Perkins NJ, et al. Preconception maternal lipoprotein levels in relation to fecundability. Hum Reprod. 2017;32(5):1055-63.

7. Schisterman EF, Mumford SL, Browne RW, Barr DB, Chen Z, Louis GM. Lipid concentrations and couple fecundity: the LIFE study. J Clin Endocrinol Metab. 2014;99(8):2786-94.

8. Badawy A, Shokeir T, Allam AF, Abdelhady H. Pregnancy outcome after ovulation induction with aromatase inhibitors or clomiphene citrate in unexplained infertility. Acta Obstet Gynecol Scand. 2009;88(2):187-91.

9. Custers IM, Steures P, Hompes P, Flierman P, van Kasteren Y, van Dop PA, et al. Intrauterine insemination: how many cycles should we perform? Hum Reprod. 2008;23(4):885-8.

10. Farhi J, Orvieto R. Cumulative clinical pregnancy rates after $\mathrm{COH}$ and IUI in subfertile couples. Gynecol Endocrinol. 2010;26(7):500-4. 
11. Ryan GL, Moss V, Davis WA, Sparks AE, Dokras A, Van Voorhis BJ. Oral ovulation induction agents combined with low-dose gonadotropin injections and intrauterine insemination: cost- and clinical effectiveness. J Reprod Med. 2005:50(12):943-50.

12. Sjaarda LA, Radin RG, Silver RM, Mitchell E, Mumford SL, Wilcox B, et al. Preconception low-dose aspirin restores diminished pregnancy and live birth rates in women with low-grade inflammation: a secondary analysis of a randomized trial. J Clin Endocrinol Metab. 2017;102(5):1495-504.

13. Diamantis E, Kyriakos G, Quiles-Sanchez LV, Farmaki P, Troupis T. The antiinflammatory effects of statins on coronary artery disease: an updated review of the literature. Curr Cardiol Rev. 2017;13(3):209-16.

14. Li JJ, Li YS, Chu JM, Zhang CY, Wang Y, Huang Y, et al. Changes of plasma inflammatory markers after withdrawal of statin therapy in patients with hyperlipidemia. Clin Chim Acta. 2006;366(1-2):269-73.

15. Plenge JK, Hernandez TL, Weil KM, Poirier P, Grunwald GK, Marcovina SM, et al. Simvastatin lowers $C$-reactive protein within 14 days: an effect independent of low-density lipoprotein cholesterol reduction. Circulation. 2002;106(12):1447-52.

16. Fulcher J, O'Connell R, Voysey M, Emberson J, Blackwell L, Mihaylova B, et al. Efficacy and safety of LDL-lowering therapy among men and women: metaanalysis of individual data from 174,000 participants in 27 randomised trials. Lancet. 2015:385(9976):1397-405.

17. Thorogood M, Seed M, De Mott K. Management of fertility in women with familial hypercholesterolaemia: summary of NICE guidance. Bjog. 2009; 116(4):478-9.

18. Kronish IM, Rieckmann N, Shimbo D, Burg M, Davidson KW. Aspirin adherence, aspirin dosage, and C-reactive protein in the first three months after an acute coronary syndrome. Am J Cardiol. 2010;106(8):1090-4.

19. Bruner-Tran KL, Osteen KG, Duleba AJ. Simvastatin protects against the development of endometriosis in a nude mouse model. J Clin Endocrinol Metab. 2009;94(7):2489-94.

20. Banaszewska B, Pawelczyk L, Spaczynski RZ, Duleba AJ. Comparison of simvastatin and metformin in treatment of polycystic ovary syndrome: prospective randomized trial. J Clin Endocrinol Metab. 2009;94(12):4938-45.

21. Banaszewska B, Pawelczyk L, Spaczynski RZ, Duleba AJ. Effects of simvastatin and metformin on polycystic ovary syndrome after six months of treatment. J Clin Endocrinol Metab. 2011;96(11):3493-501.

\section{Publisher's Note}

Springer Nature remains neutral with regard to jurisdictional claims in published maps and institutional affiliations.

Ready to submit your research? Choose BMC and benefit from:

- fast, convenient online submission

- thorough peer review by experienced researchers in your field

- rapid publication on acceptance

- support for research data, including large and complex data types

- gold Open Access which fosters wider collaboration and increased citations

- maximum visibility for your research: over $100 \mathrm{M}$ website views per year

At $\mathrm{BMC}$, research is always in progress.

Learn more biomedcentral.com/submissions 